\title{
Evaluation of the Readiness for E-Learning from the Viewpoints of the Students and Professors of Allameh Tabataba'i University
}

\author{
Esmaeil Aslani, ${ }^{1,}$ Mehdi Babakhani, ${ }^{1}$ Azad Allah Karami, ${ }^{2}$ and Mohammad Hassan Amirteimori ${ }^{3}$ \\ ${ }^{1}$ Master degree of Educational Technology, Faculty of Psychology and Educational Science, Allameh Tabataba'i University \\ ${ }^{2}$ Ph.D. Candidate in Educational Technology, Faculty of psychology and Educational Science, Allameh Tabataba'i University \\ ${ }^{3}$ Curriculum Planning, Faculty Member, Department of Educational Technology, Faculty of Psychology and Educational Science, Allameh Tabataba'i University \\ "Corresponding author: Esmaeil Aslani, Master degree of Educational Technology, Faculty of psychology and Educational Science, Allameh Tabataba'i University, E-mail: \\ aslanii1989@gmail.com
}

Received 2015 July 19; Revised 2016 March 19; Accepted 2016 March 26.

\begin{abstract}
Introduction: Achieving e-learning requires a comprehensive study on different aspects of e-learning readiness. The present study aimed to evaluate the readiness for e-learning from the viewpoints of the students as well as faculty members of Allameh Tabataba'i University.

Methods: This is a survey research and the statistical population was all professors and students of Allameh Tabataba'i University in 2014 - 2015 section. One hundred and fifty (150) students were selected through simple random clustering, and 50 professors were selected through convenient sampling as the population of the study. The instrument of study was "evaluation of readiness for e-learning in Iranian university" questionnaire and its content and face validity were verified by professionals, and its reliability was measured through Cronbach's coefficient alpha which was $(0.75,0.79)$. To analyze the data, descriptive and mean, SD statistics (independent T-test and Freedman test) were used.

Results: The result showed that the degree of the hard readiness (3.6 mean) and total readiness (3.33 mean) was in the desirable level and soft readiness (3.07 mean) was in the moderate level from the students' viewpoint and the soft, monitoring, coordinating and supporting and total readiness (respectively, 2.36, 1.98, 2.81 mean) were evaluated as undesirable from the viewpoint of the professors, but their evaluation in hard readiness (4.1 mean) indicated that they confirm the status of the university in this readiness, which is desirable.

Conclusions: Evaluation of the readiness for e-learning in the universities provided information on the strengths and weaknesses of this center in achieving e-learning.
\end{abstract}

Keywords: E-Learning, Readiness, Implementation, University, Student, Professor

\section{Introduction}

Information and communication technology (ICT) is an indispensable part of the contemporary world. In fact, culture and society have to be adjusted to meet the challenges of the knowledge age (1). Advances in information technology, and its combination with changes in society, have created new ideas in teaching and learning. These changes have a great effect on teaching instructional and learning systems (2). Supporting the use of information and communication technology in the education sphere, including planning, developing content, teaching-learning methods, especially in educational environments, is one of the most important requirements to improve the quality of teaching and learning (3). In the age of accelerating changes and revolution, the unique role of e-learning in the development of education is apparent. Universities also make serious efforts to design, establish and develop e-learning systems to stay ahead of the caravan users of technology in education (4). E-learning can solve a lot of problems in the society, which includes the growing needs of education, lack of equal access to educational centers and content, lack of economic facilities, lack of qualified teachers according to students' needs, high costs of education and training services (5).

Romiszowski's definition of e-learning is somewhat more comprehensive than other existing definitions. According to this definition, e-learning encompasses all educational activities that are carried out by individuals or groups working online or offline, and synchronously or asynchronously instruction based on web via networked or standalone computers and other electronic devices (6). These various types or modalities of e-learning activity are represented in Figure 1.

One of the most important changes in the area of education in the information age is formation of studentcentered education together with teacher-centered education (one) and to supplement it, the advent of e-learning as a subset of distance learning, has provided the groundwork for more widespread use of learner-centered educa- 


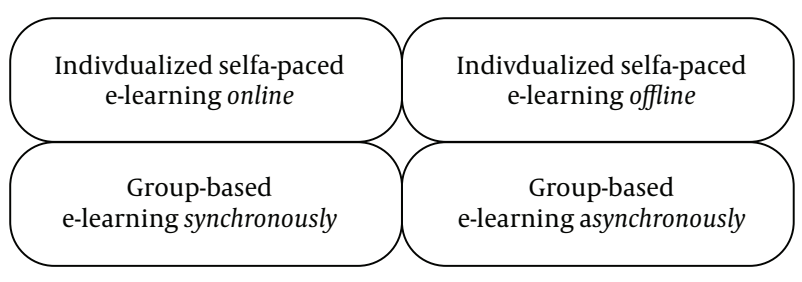

Figure 1. E-Learning Modalities (7)

tion and other changes in educational practices (8). The traditional methods of applying activities in educational institutions, as in other organizations in contemporary society for traditional purposes and modes of operation are being challenged and changed. Fundamental changes incurred due to the advent of information and communication technology in recent decades significantly affected various aspects of higher education (9). One of the changes that have been observed in recent years is increasing use of information technology in various fields, including education field with efforts to develop virtual universities and distance learning. But achieving e-learning and virtual universities requires meeting the conditions from different aspects, which is systematically called readiness for elearning. E-learning implementation requires physical infrastructure, technical expertise and psychological readiness (10), and it is obvious that realization of e-learning have to be handled and evaluated. Different aspects of readiness both in infrastructure and in terms of policy advocacy and human resource readiness, for officials and policymakers, take appropriate policy and planning development projects to create a synergic and balanced environment for the realization of e-learning. Montazer and Darab (11) categorized general framework of e-learning readiness assessment into three parts:

1. Hard readiness: this section applies to all aspects of the required hardware and communication equipment to provide e-learning.

2. Soft readiness: this section represents all the required soft factors including software technologies (regulations, procedures, rules, etc.) to create and support online learning environments.

3. Monitoring, coordination and supporting readiness: while the previous two mentioned are related to the internal functioning of the educational system, this readiness is related to making the interactions and coordination among components in the aforementioned sections. Monitoring division includes two parts: monitoring process and monitoring of training process.

Machado (12) defined e-learning readiness as ability of organizations and capacities of education stakeholders (management, key personnel, teachers and students) to become successful participants in e-learning and virtual university. E-learning readiness with the aim of adopting e-learning can be known as physical or mental preparation for e-learning experience or practice. Readiness assessment for e-learning allows officials and policymakers to take appropriate policy and implement development projects with the participation of all stakeholders (13). Evaluation of e-learning readiness is preliminary of its development and readiness or organizations measured to achieve the benefits of e-learning. In this context, many researchers focused on assessing the readiness of universities, institutions and organizations to implement e-learning system (14). Several studies were carried out on examining and evaluating e-learning readiness in different institutions and some of them are mentioned below.

Kamalian and Fazel, in order to determine the possibility of running e-learning projects and awareness which is the prerequisite of this type of learning, conducted a research in the University of Sistan-Baluchistan. Some factors such as required technology for e-learning, continuous communications and skills, motivation, ability to learn through media, online discussions and important issues for the success of e-learning were studied in this research. The results showed that students had relative readiness for participation in e-learning (14).

Zargordi et al. (15) examined the prerequisites and feasibility of implementation of e-learning in students of Fasa University of Medical Science. The addressed themes in this study were: the most important factors for the success of e-learning, the ability to learn through the media, access to technology, web-based conversation and motivation. The results of their study showed that students have the ability and an appropriate relative readiness in the field of e-learning.

Nasiri and Fathi Vajargah (16) study was entitled feasibility of the establishment of virtual training in the framework of the Ministry of Education in terms of technical, human, financial, physical, organizational and cultural resources, and implementation of e-learning system in this area. It was found from the view point of experts training the country's Ministry of Education, that it is possible to establish virtual training in the ministry.

Momeni Rad (17) was determined to assess the quality of e-learning courses in the field of Engineering Information Technology of Khajeh Nasir University based on researcher-made checklist such as interaction, instructional design, feedback, content, accessibility and multimedia-based learning management system. The results showed that the mean of instructional standards were in relatively desirable range.

The results of Montazer and Darab (11) study on e- 
Learning Readiness Assessment of Tarbiat Modarres University, by using native model assessment of Iranian universities, showed that the mean of readiness of the assessed components (soft, hard and monitoring, coordination and supporting) in Tarbiat Modarres University was 8.2 (from 10), which reflected the lack of readiness and serious weakness in the implementation of e-learning.

Mansorpor in his thesis by using Darab (18) model in three aspects: soft, hard and monitoring, coordination and supporting readiness, assessed the e-learning readiness in Ahvaz Payame Noor University and the results showed that the mean for e-learning readiness (32.06) was less than 50 and thus the university in terms of all the examined groups in three aspects, was low (19).

Maleki Marvdasht et al. (20) study was aimed at assessing the readiness of students of Urmia University to participate in e-learning system. The study examined six factors, which include: access to technology, continuous communications and skills, motivation, ability to learn through media, online discussions and important issues for the success of e-learning. The results showed that the participating students of Urmia University had moderate level of readiness to participate in e-learning and there was significant difference between readiness of the bachelor and master students.

Keshavarzi et al. (21) aimed to study the feasibility of elearning in Islamic Azad University of Marvdasht in terms of faculty, students and staff. In the study, they determined hardware and software equipment in the development of virtual training and courses as well as the interest rates, and the results showed that the possibility of establishing virtual education from the viewpoint of the officials and professors as well as students of Marvdasht Islamic Azad University is at a high level.

Masod Niya (22), in his dissertation, examined the readiness of e-learning in Yazd international campus of Shahid Sadoughi. A model adapted from the Khan with three frameworks: organizational, technology and audience analysis was used to assess the readiness. The results showed that the readiness status of Shahid Sadoughi University is desirable.

Jariangprasert (23) studied on the understanding and readiness of the faculty members and students of business and administration college of Chiang Mai University for the use of e-learning for their teaching. Results showed that the students had more understanding of e-learning than the faculties. Both faculties and students thought that e-learning is very useful, but neither of them is ready for its use, therefore, it needs more support.

Sadik's (24) study aimed to determine the readiness of faculties at South Valley University in Egypt for the implementation of e-learning in their teaching. This study re- ported that three components: attitude, experience and competence, are effective in people's readiness to develop and implement e-learning and in terms of hardware equipment, they are ready to accept e-learning courses at the university.

Robertson (25) in his study, examined the readiness of veterinary students. The results showed that about threequarter of the group lack the required character and skills to succeed in technology-based learning. The researcher suggested that technical skills are one of effective criteria which form the readiness and learner's success in elearning.

Allameh Tabataba'i University has struggled with the provision of hardware and software for e-learning in recent years. According to the current review of the literature on this issue, it was found that many researchers have assessed the readiness of institutions, universities and various organizations to implement e-learning system and specified the strengths and weaknesses of these centers for e-learning readiness. Due to the policies of Allameh Tabataba'i University for designing e-learning, it is necessary to assess the readiness of e-learning at the university. This study examined readiness of e-learning at Allameh Tabataba'i University, to identify the prerequisites, issues, conditions and the capabilities. The research questions are as follows:

1. From the students' viewpoint, how ready is Allameh Tabataba'i University in implementing e-learning?

2. From the professors' viewpoint, how ready is Allameh Tabataba'i University in implementing e-learning?

\section{Methods}

Due to the aim of the study which is evaluation of the readiness of Allameh Tabataba'i University to implement elearning, this study was a survey research and the statistical population was all professors and students of Allameh Tabataba'i University in 2014 - 2015 section.

The population of study was 150 students and 50 professors who were chosen by cluster and convenience sampling and the questionnaire of e-learning readiness was distributed among them. Entrance criteria were schooling in Allameh Tabataba'i University for students and been faculty member for professors, and the participants were given a choice to withdraw from the study at any time. To collect data, evaluation of electronic readiness of Iranian universities questionnaire was used. Darab (18) introduced native models for assessing e-learning readiness in universities by evaluating different models and relying on comparative studies and analysis of information obtained from indigenous studies. Then, the indexes and indicators of native model through interviews and questionnaires 
was tested and validated. He used five-point Likert scale (with a scale of 1 for strongly disagree and 5 for strongly agree). Questionnaires were distributed to more than sixty experts in the e-learning and higher education. The questionnaire consisted of three main components, including soft, hard and monitoring, coordination and supporting readiness. This was used to collect the viewpoints of students and professors in two versions. E-readiness assessment questionnaire contains 16 questions from the students' perspective and assessed both soft and hard readiness, and E-readiness assessment questionnaire for professors contains 34 questions and include soft, hard and monitoring, coordination and supporting readiness. Face and content validity of the questionnaire was verified by five experts in the field of educational technology and the reliability of the questionnaire was measured by Cronbach's alpha test. Reliability of the student questionnaire was 0.75 and that of the professor was 0.79. Due to the obtained reliability (greater than 0.7), it can be said that the questionnaires have sufficient reliability.

To respect the ethical and informed consent of the research participants, they were aware of the aspects of the research which might have reasonably affected their decision to either participate or not in the study and the questionnaires had no name because of privacy.

\section{Results}

In this study, the percentage of students was seperated by gender, $55 \%$ ( 83 persons) were female and $44.6 \%$ ( 67 persons) were male. $65.3 \%$ (98 persons) were in the bachelor level, $23.3 \%$ (35 persons) in the master level and 11.3\% (17 persons) were in doctoral level. $72 \%$ (36 participants) of professors were male and $28 \%$ ( 14 persons) were female. The responses in the first research question were examined by one sample t-test (Table 1).

(From the students' viewpoint, how ready is Allameh Tabataba'i University in implementing e-learning?)

Based on the result of T-test and a significant level in Table 1 and due to the fact that the observed mean in the hard and total readiness of e-learning from the students view point is greater than the assumed mean or average questionnaire Likert scale (3), it can be said that with 99 confidence intervals, the students assessed hard and total readiness desirably. But a significant level in soft readiness components indicates that students identified that the soft readiness of Allameh Tabataba'i University is moderate. Friedman test was used to prioritize implementation of e-learning from the students and professors' viewpoint. The reason for using the non-parametric test is the failure of Mauchly's test of sphericity assumptions to use a within-subjects one-way ANOVA.
As seen in Table 2 the observed Chi-square value is 199.90 and due to the significant level of $\mathrm{P}<001$, it can be said that there is significant difference between the variable from the students' perspective. Also, component weights showed that student's priority in implementing elearning at first is hard readiness and then soft readiness.

The responses to the second research question was examined by one sample t-test (From the professors' viewpoint, how ready is Allameh Tabataba'i University in implementing e-learning?) (Table 3).

Based on the T-test result and the significant level shown in Table 3 and according to the observed average in the soft, hard and monitoring, coordination and supporting readiness components from the professor's point of view, they are smaller than the assumed mean or average questionnaire Likert scale (3), and it can be said that by 99 confidence intervals, the professors assessed soft, hard and monitoring, coordination and supporting readiness undesirably. But the T-test result and the significant level shown in Table 3 showed that the professors assessed hard readiness desirably.

As shown in Table 4 the observed Chi-square value is 58.61 and due to the significant level of $\mathrm{P}<001$, it can be said that there is significant difference between the variables from the professors' perspective. Also, component weights showed that professor's priorities for implementing e-learning are respectively, hard, soft and finally monitoring, coordination and supporting readiness. Wilcoxon test was used to examine the quality difference between the two-by-two variable from the professors perspective.

As shown in Table 5 the observed $Z$ value for the differences between soft and hard readiness is 98.4 , and due to the significance level of $\mathrm{P}<001$, it can be said that there is a significant difference between these two variables. Also, $\mathrm{Z}$ value and significance level are respectively -3.39 and $\mathrm{P}<$ 001 in examining the differences between soft and monitoring, coordination and supporting readiness variables, and are $4-4.89$ and $\mathrm{P}<001$ in hard and monitoring, coordination and supporting readiness variable. So it can be said that there is significant difference between the two-by-two variables.

\section{Discussion and Conclusions}

The present study aimed to evaluate the readiness of e-learning from the viewpoints of the students as well as faculty members of Allameh Tabataba'i University.

Results show that hard and total readinesses are in desirable level and soft readiness is in moderate level from the viewpoint of the students. Also, component weights showed that student's priority for implementing 
Table 1. One Sample T-Test Results for Students View on E-Learning Readiness and Its Dimensions

\begin{tabular}{|c|c|c|c|c|c|}
\hline Variable & $\mathbf{N}$ & Mean \pm SD & $\mathbf{t}$ & Df & P Value \\
\hline Soft reediness & 150 & $3.07 \pm 0.54$ & 1.66 & 149 & 0.099 \\
\hline Hard reediness & 150 & $3.60 \pm 1.06$ & 6.97 & 149 & $<0.001$ \\
\hline E-learning reediness & 150 & $3.33 \pm 0.67$ & 6.15 & 149 & $<0.001$ \\
\hline
\end{tabular}

Table 2. Friedman's Analysis for Prioritizing Dimensions of the Students' Perspective

\begin{tabular}{l|c|c|c|c|c|c}
\hline \multirow{2}{*}{ Dimension } & \multicolumn{3}{|c}{ Statistical Indicators } & Chi-Square & Df & P Value \\
\cline { 2 - 7 } & Rank & Weight & 1.32 & 150 & 199.90 & 2 \\
Soft reediness & 2 & 1.68 & & & 201 \\
\hline
\end{tabular}

Table 3. One-Sample T-Test Results for Professor View on E-Learning Readiness and Its Dimensions

\begin{tabular}{|c|c|c|c|c|c|}
\hline Variable & $\mathbf{N}$ & Meane $\pm S D$ & $\mathbf{t}$ & Df & P Value \\
\hline Soft reediness & 42 & $2.36 \pm 0.50$ & -8.19 & 41 & $<001$ \\
\hline Hard reediness & 42 & $4.10 \pm 0.67$ & 10.62 & 41 & $<001$ \\
\hline Monitoring, coordination and supporting reediness & 42 & $1.98 \pm 0.57$ & -11.32 & 41 & $<001$ \\
\hline E-learning reediness & 42 & 2.81 & -3.03 & 41 & 0.004 \\
\hline
\end{tabular}

Table 4. Friedman's Analysis for Prioritizing Dimensions of the Professors' Perspective

\begin{tabular}{|c|c|c|c|c|c|c|}
\hline \multirow[b]{2}{*}{ Dimension } & \multicolumn{6}{|c|}{ Statistical Indicators } \\
\hline & Rank & Weight & $\mathbf{N}$ & Chi-Square & Df & PValue \\
\hline Soft reediness & 2 & 1.76 & \multirow{3}{*}{42} & \multirow{3}{*}{58.61} & \multirow{3}{*}{2} & \multirow{3}{*}{$<001$} \\
\hline Hard reediness & 1 & 2.93 & & & & \\
\hline $\begin{array}{l}\text { Monitoring, } \\
\text { coordination and } \\
\text { supporting reediness }\end{array}$ & 3 & 1.31 & & & & \\
\hline
\end{tabular}

Table 5. Results of Wilcoxon Test for Differences Between Two-By-Two Variables

\begin{tabular}{lccc}
\hline Variable & Z & P Value \\
\hline Soft reediness & Hard reediness & -4.98 & $<001$ \\
\hline Soft reediness & $\begin{array}{c}\text { Monitoring, coordination and } \\
\text { supporting reediness }\end{array}$ & -3.39 & $<001$ \\
\hline Hard reediness & $\begin{array}{c}\text { Monitoring, coordination and } \\
\text { supporting reediness }\end{array}$ & -4.89 & $<001$ \\
\hline
\end{tabular}

e-learning at first is hard and then soft readiness. According to these findings, Allameh Tabataba'i University is ready to participate in e-learning. The results of this study are in line with that of Maleki Marvdasht et al. (20), Zargordi et al. (15), Kamalian and Fazel (14) and Karami (26).
From the Professors' viewpoint, it was also shown that soft readiness, monitoring, coordination and supporting readiness, and total readiness were undesirable. In line with these results, are results of the studies of Darab (18), Nori et al. (27), Jariangprasert (23) and Robertson (25). Their evaluation of the hard readiness indicated that they assessed it desirably. In line with these results, are results of studies of Sadik (24), Maleki Marvdasht et al. (20), Zargordi et al. (15), Kamalian and Fazel (14), Karami(26) and Rahimi Dost and Razavi (28) with regards to component weights which showed that professor's priority for implementing e-learning respectively are hard, soft and finally monitoring, coordination and supporting readiness.

From the result, it can be shown that all the hardware, communications and equipment are related to the hard 
readiness. Implementation of e-learning depends on the Internet and appropriate broadband to connect and get the information. Bugs appearing in this case makes communication in e-learning not to be well established. The desirability of hard readiness in the university has different reasons: High-speed Internet access for students on campus, central site and dorm, the suitability of the number of computers in faculties and a personal computer.

All the factors reviewed in soft readiness were human resources, management, regulations, standards, finance, security, cultural and educational content, and policies which support the environment. E-learning will not be successful if the necessary administrative support is not provided for students. Due to the assessment of soft readiness from students' and professors' of Allameh Tabataba'i University viewpoint, the following reasons can be cited for this result: Relative access to the electronic library, magazines and databases, failure to produce and deliver electronic content and educational software, and unfamiliarity of professors with software for electronic content production.

Course managers must be informed about the readiness and quality of student learning and the ability to evaluate the performance of learners, assessment content provided, as well as the quality of their teaching and learning environment in monitoring, coordination and supporting readiness. This study showed that, Allameh Tabataba'i University does not have enough readiness in this dimension, which reveals lack of attention of authorities and faculties. So, it can be reported that in most departments, authorities of the computer, periodicals and people associated with this sector, do not have higher degree and it is an obstacle in the progress of information technology.

In general, while the professors and students have adequate hard readiness, it can be said that Allameh Tabataba'i University have appropriate and necessary conditions to implement the e-learning environment. Although, the components: soft and monitoring, coordination and supporting readiness in both group were undesirable, it is essential that executives of the software technologies should try to promote the trends, laws and regulations that are needed to create and support online learning environments to the standard level.

The following suggestions are presented to provide the infrastructure for the implementation of e-learning courses at Allameh Tabataba'i University.

- Equipping the university with sufficient and update resources for teaching, learning and assessment of the process in virtual courses.

- Organizing appropriate instructional content and providing conditions to have easy access to appropriate educational content, before beginning the virtual courses.
- Strengthening the cultural, scientific and educational aspects through seminars, workshops and training courses.

- Providing appropriate training courses for professors on the requirements for the electronic learning environment. The content of the training courses may be associated with familiarity with the application of electronic content production, online tests, evaluation of e-learning and so on.

\section{Acknowledgments}

The authors are thankful to the students and professors of Allameh Tabataba'i University that participated in this study.

\section{Footnotes}

Authors' Contribution: This study is a product of the intellectual context of the authors; and the authors contributed in various degrees to the method employed, the actual writing, as well as the research setting. Study concept and design: Esmaeil Aslani and Mehdi Babakhani; Analysis and interpretation of data: Esmaeil Aslani and Azad Allah Karami; Drafting of the manuscript: Esmaeil Aslani and Mehdi Babakhani; Critical revision of the manuscript for important intellectual content: Azad Allah Karami, Amir Teymori, Esmaeil Aslani and Mehdi Babakhani; Statistical analysis: Azad Allah Karami and Esmaeil Aslani.

Conflict of Interest: Fund for this study is not attributed to any institution or organization.

\section{References}

1. Yusuf MO. Information and Communication Technology and Education: Analysing the Nigerian National Policy for Information Technology. Int Educ J. 2005;6(3):316-21.

2. Feizi K, Behzadi A. A model to assess the readiness of E-learning systems in financial organizations. Res J Technol. 2014;8(3):193-204.

3. Khazaei K, Eshvarnezhad K. The relationship between information and communication technology skills with elements of self-directed student learning. Q J Inf Commun Technol Educ. 2012;3(1):45-61.

4. Zare Bidaki M. E-learning Development challenges in medical universities of Iran. J Med Educ Dev Center. 2013;10(4):382-5.

5. Golband F, Mojtahedzade R, Hosseni A, Mir Hosseini F, Bigdeli S. Factors affecting the success of E-learning from the perspective of virtual postgraduate students of Tehran University. Educ Strateg Med Sci J. 2013;7(2):93-7.

6. Rahimi Dost Q. How was the experience of e-learning project? Challenges in e-learning project. Q Lib Inf Sci. 2007;10(2):337-55.

7. Naidu S. E-Learning: A Guidebook of Principles, Procedures and Practices. New Delhi: Commonwealth Educational Media Center for Asia (CEMCA), and the Commonwealth of Learning; 2006. 
8. Hosseini S, Nori A, Zabihi M. Acceptance of e-learning in higher education: application of the theory, technology acceptance model and the quality of electronic services. J Res Plan High Educ. 2013;19(67):136-11.

9. Uiukan G. Managerial issues in open and distance education organization. New York: Sage publication; 2005.

10. Ouma GO, Awuor FM, Kyambo B. E-Learning Readiness in Public Secondary Schools in Kenya. Eur J Open Distance E-Learn. 2013;16(2).

11. Montazer Q, Darab B. Assess the readiness of E-learning at Tarbiat Modarres University. Fourth National Conference and the first International Conference on E-Learning. Tehran. Iran University of Science and Technology; 2010. pp.1-18.

12. Machado C. Developing an e-readiness model for higher education institutions: results of a focus group study. Br J Educ Technol. 2007;38(1):72-82. doi: 10.1111/j.1467-8535.2006.00595.x.

13. Borotis S, Poulymenakou A. E-learning readiness components: Key issues to consider before adopting e-learning interventions. World Conference on E-Learning in Corporate, Government, Healthcare, and Higher Education. .

14. Kamalian A, Fazel A. Check prerequisites and feasibility of the implementation of thee-learning system. J Educ Technol. 2009;4(1):13-27.

15. Zargordi B, Boedbar A, Leqaei T. Prerequisite's feasibility study and elearning projects in Fasa University of Medical Sciences. J Med Educ Dev. 2010;4(11):11-7.

16. Nasiri F, Fathi Vajargah K. The feasibility of the establishment of the Ministry of Education's virtual training. Tehran: Faculty of Education and Psychology Shahid Beheshti University; 2003.

17. Momeni Rad A. Check the quality of the IT field of E-learning in Khajeh Nasir University based on E-Learning standards. Tehran: Faculty of psychology and pedagogy in Allameh Tabataba'i University; 2009.

18. Darab B. Designing the Evaluation of the readiness of E-learning in Iranian Universities. Tehran: Tarbiat Modares University; 2009.

19. Mansorpor A. E-learning readiness assessment of Payam Noor Univer- sity in Ahvaz. Tehran: Faculty of Psychology and Educational Sciences of Allameh Tabataba'i University; 2011.

20. Maleki Marvdasht M, Qale'i A, Mosavi S. Evaluation of Urmia university students willing to participate in E-learning system. QJ Epistemol. 2011;18(3):147-66.

21. Keshavarzi M, Salahi M, Heydari S, Salehi M, Amiriyan Zadeh M. Assessment of the Feasibility of E-learning in the Faculty of Educational Sciences and Psychology at Islamic Azad University of Marvdasht. Magazine E-learn Distribut Acad. 2012;4(1):20-7.

22. Masod Niya M. Assess the readiness of the E-learning in Medical Sciences of Shahid Sadoqi international university. Tehran: Faculty of Psychology and Educational Sciences of Allameh Tabataba'i University; 2012.

23. Jariangprasert $\mathrm{N}$. The opinion of faculty of business administration lecturers and students, Chiang Mai University about the use of ELearning. Songklanakarin J Soc Sci Human. 2003;9(2):136-45.

24. Sadik A. The readiness of faculty members to develop and implement e-learning: The case of an Egyptian university. Int J ELearn. 2007;6(3):433.

25. Robertson I. Technology-based learning: problematising VET students' preferences and readiness. Refereed Paper Presented at 2007 AVETRA Conference. .

26. Karami A. Assessment and E-learning in higher education system's qualitative analysis capabilities. Tehran: Tarbiat Modarres University in Tehran; 2006.

27. Nori A, Kahani M, Afkhami H. Assess the E-readiness of Mashhad University with an emphasis on access to information. Information \& Knowledge Technology Conference. Mashhad. Ferdosi University; 2007. pp.1-8.

28. Rahimi Dost Q, Razavi A. Measuring readiness for e-learning project. JEduc. 2012;19(2):145-66. 